\title{
Electrical leakage phenomenon in heteroepitaxial cubic silicon carbide on silicon
}

\author{
Aiswarya Pradeepkumar ${ }^{1}$, Marcin Zielinski², Matteo Bosi ${ }^{3}$, Giovanni Verzellesi ${ }^{4}$, \\ D. Kurt Gaskill ${ }^{5}$, Francesca lacopi ${ }^{1,}$ a) \\ ${ }^{1}$ University of Technology Sydney, School of Electrical and Data Engineering, NSW 2007, Australia \\ ${ }^{2}$ NOVASiC, Savoie Technolac, Arche Bât. 4, BP 267, 73375 Le Bourget du Lac Cedex, France \\ ${ }^{3}$ IMEM-CNR Institute, Parco Area delle Scienze 37/A, 43124 Parma, Italy \\ ${ }^{4}$ Dipartimento di Scienze e Metodi dell'Ingegneria (DISMI) and En\&tech, University of Modena and Reggio Emilia, Reggio \\ Emilia, Italy \\ ${ }^{5}$ US Naval Research Laboratory, Washington, DC 20375, USA
}

\begin{abstract}
Heteroepitaxial 3C-SiC films on silicon substrates are of technological interest as enablers to integrate the excellent electrical, electronic, mechanical, thermal and epitaxial properties of bulk silicon carbide into well-established silicon technologies. One critical bottleneck of this integration is the establishment of a stable and reliable electronic junction at the heteroepitaxial interface of the n-type $\mathrm{SiC}$ with the silicon substrate. We have thus investigated in detail the electrical and transport properties of heteroepitaxial cubic silicon carbide films grown via different methods on low-doped and high-resistivity silicon substrates by using van der Pauw Hall and transfer length measurements as test vehicles. We have found that $\mathrm{Si}$ and $\mathrm{C}$ intermixing upon or after growth, particularly by the diffusion of carbon into the silicon matrix, creates extensive interstitial carbon traps and hampers the formation of a stable rectifying or insulating junction at the $\mathrm{SiC} / \mathrm{Si}$ interface. Although a reliable $\mathrm{p}-\mathrm{n}$ junction may be not realistic in the $\mathrm{SiC} / \mathrm{Si}$ system, we can achieve, from a point of view of the electrical isolation of in-plane $\mathrm{SiC}$ structures, leakage suppression through the substrate by using a highresistivity silicon substrate coupled with deep recess etching in between the $\mathrm{SiC}$ structures.
\end{abstract}

\section{INTRODUCTION}

Epitaxial cubic silicon carbide films on silicon (3C-SiC/Si and hereafter $\mathrm{SiC} / \mathrm{Si}$ ) have attracted extensive interest for semiconductor device applications such as high-voltage, highfrequency diodes, and heterojunction bipolar transistors. ${ }^{1}$ This is because these structures offer access to the properties of $\mathrm{SiC}$, such as its wide band gap and high thermal conductivity, on more conventional silicon substrates. ${ }^{2}$ Despite these significant properties, no 3C-SiC based devices are currently commercially available ${ }^{3}$ and this is due in part to problems associated with $\mathrm{SiC} / \mathrm{Si}$ junctions. ${ }^{4-6}$

We have recently shown that the expected $p$-n junction between a $p$-type silicon substrate to the $3 \mathrm{C}$-SiC, naturally grown as unintentionally n-type, is either non-existing or very unstable so that severe leakage or even plain shorting of the epitaxial silicon carbide to 
the underlying silicon substrate ${ }^{1}$ is typically found. ${ }^{7,8}$ The absence of a stable p-n junction at the $\mathrm{SiC} / \mathrm{Si}$ interface could pose important limitations to the applications of $3 \mathrm{C}-\mathrm{SiC}$ in power electronics, harsh environment, MEMS, LEDs, graphene-based devices, etc. ${ }^{2}$

To date, a few studies have been conducted on the properties of $\mathrm{SiC} / \mathrm{Si}$ junctions, however, electrical leakage is linked to stacking fault defects in $3 \mathrm{C}-\mathrm{SiC}{ }^{2}$ Moreover, studies of strained heterostructures have shown that the substantial tensile strain generated from the lattice and thermal expansion coefficient mismatch between $3 \mathrm{C}-\mathrm{SiC}$ and silicon may reduce the band gap of the SiC. ${ }^{9}$ Nevertheless, a detailed explanation of the leakage/shorting phenomenon, and the impact of this challenge on the electrical properties of $3 \mathrm{C}-\mathrm{SiC}$ layers are poorly documented in the literature.

Suemitsu et al. have attempted the growth of $\mathrm{SiC}$ onto an intermediate insulating $4 \mathrm{H}$ AlN layer on silicon in order to avoid the diffusion of silicon atoms from the substrate through the $\mathrm{SiC}$ layer, which also hampered the graphitization of the $\mathrm{SiC}$ surface. ${ }^{10}$ This indicates that the instability of the SiC/Si interface affects potential applications in more than one way.

In this work, we develop an in-depth understanding of the historically overlooked leakage problem in 3C-SiC on $\mathrm{Si}$ heterojunction system, by studying in detail the electrical behaviour of $\mathrm{SiC}$ films epitaxially grown on different silicon substrates under different growth conditions. Based on the findings, we propose a model for the source of electrical and electronic instability of the p-n junction in $\mathrm{SiC} / \mathrm{Si}$. Also, based on our understanding of $\mathrm{SiC} / \mathrm{Si}$, this work demonstrates a method for solving the problem of in-plane shorting or leakage for isolated $\mathrm{SiC}$ mesas or interdigitated structures on silicon.

\section{EXPERIMENT}

In this work we use unintentionally doped (thus n-type), $500 \mathrm{~nm}$ thick, NOVASiC 3C$\operatorname{SiC}(100)$ films epitaxially grown on $527 \mu \mathrm{m}$ low-doped p-type $\operatorname{Si}(100)$ having resistivity ranging from 1 to $10 \Omega \mathrm{cm}$ as well as high-resistivity (typically n-type, $>10 \mathrm{k} \Omega \mathrm{cm}$ ) $\mathrm{Si}(100)$ substrates. ${ }^{11}$ A second partner, IMEM-CNR, supplied 3C-SiC(100) films grown on $279 \pm 25$ $\mu \mathrm{m}$ p-type $\mathrm{Si}(100)$ with resistivity ranging from 1 to $5 \mathrm{~m} \Omega \mathrm{cm} .{ }^{12}$ Additionally, we have also tested $5 \mu \mathrm{m}$ thick SiC films from IMEM-CNR prepared on $0^{\circ}$ and $6^{\circ}$ off-cut towards (110) Si(100) substrates. ${ }^{13}$ Note that the $3 C-S i C(100)$ films from both NOVASiC and IMEM-CNR are grown at $1300-1400{ }^{\circ} \mathrm{C}$. Table I summarizes the samples studied in this work.

a) Author to whom correspondence should be addressed. Electronic mail: francesca.iacopi@uts.edu.au 
For electrical characterization, we diced the $\mathrm{SiC} / \mathrm{Si}$ wafers into $1.1 \times 1.1 \mathrm{~cm}^{2}$ coupons, and sputtered $150 \mathrm{~nm}$ thick nickel contacts (not annealed) onto the four corners using a custommade shadow mask (Fig. 1(a)). We estimated the electrical properties such as the carrier concentration, carrier mobility, and sheet resistance at room temperature by performing van der Pauw Hall measurements on the $\mathrm{SiC} / \mathrm{Si}$ samples as well as on representative bare $\mathrm{Si}$ substrates using an Ecopia HMS 5300 Hall Effect Measurement System. Scanning Electron Microscopy (SEM) using Zeiss supra 55VP SEM system operating at $10 \mathrm{kV}$ characterized the surface morphology of the epilayers. Moreover, we performed simulations to model the leakage phenomenon and its influence on the electrical conduction using the Synopsys Sentaurus Device ${ }^{\mathrm{TM}}$ simulator for the $3 \mathrm{C}-\mathrm{SiC}$ on low-doped silicon.

Van der Pauw structures of $\mathrm{SiC}$ on high-resistivity $\mathrm{Si}$ were exposed to Inductively Coupled Plasma (ICP) etching using $\mathrm{SF}_{6}$ gas and oxygen to remove the $\mathrm{SiC}$ layer using the $\mathrm{Ni}$ contacts as a hard mask followed by an Energy Dispersive X-Ray Analysis, and the Hall measurements were repeated at room temperature. Furthermore, $\mathrm{SiC}$ on high-resistivity $\mathrm{Si}$ samples were patterned into transfer length measurement (TLM) structures consisting of 300 $\mathrm{nm}$ thick, $500 \mu \mathrm{m}$ wide aluminium contacts deposited using e-beam evaporation (not annealed) followed by acid etching of aluminium and reactive-ion etching of SiC. Current-voltage at room temperature using HP4145B semiconductor parameter analyser measured the leakage resistances. Afterwards, the silicon in between the $\mathrm{SiC}$ pillars for both the van der Pauw and TLM structures of $\mathrm{SiC}$ on high-resistivity $\mathrm{Si}$ were subsequently etched using ICP, and all measurements were repeated.

TABLE I. Summary of the samples used.

\begin{tabular}{lcccc}
\hline \hline Samples & Supplier & $\begin{array}{c}\text { Si resistivity } \\
(\Omega \mathrm{cm})\end{array}$ & $\begin{array}{c}\text { Si thickness } \\
(\mu \mathrm{m})\end{array}$ & $\begin{array}{c}\text { SiC thickness } \\
(\mu \mathrm{m})\end{array}$ \\
\hline $\mathrm{SiC} / \mathrm{p}-\mathrm{Si}$ & NOVASiC & $1-10$ & 527 (on-axis) & 0.5 \\
$\mathrm{SiC} / \mathrm{high}-\mathrm{resistivity} \mathrm{Si}$ & NOVASiC & $>10 \mathrm{k}$ & 235 (on-axis) & 0.5 \\
$\mathrm{SiC} / \mathrm{p}-\mathrm{Si}$ & IMEM-CNR & $1-5 \mathrm{~m}$ & $279 \pm 25$ (on-axis) & 0.5 \\
$\mathrm{SiC} / \mathrm{p}-\mathrm{Si}$ & IMEM-CNR & $1-5 \mathrm{~m}$ & $279 \pm 25$ (on-axis) & 5.0 \\
$\mathrm{SiC} / \mathrm{p}-\mathrm{Si}$ & IMEM-CNR & $1-5 \mathrm{~m}$ & $279 \pm 25\left(6^{\circ}\right.$ off-axis $\left.(110)\right)$ & 5.0 \\
\hline \hline
\end{tabular}




\section{RESULTS AND DISCUSSION}

\section{A. 3C-SiC on low-doped silicon}

\section{Results}

TABLE II. Hall measured transport characteristics at room temperature. Results are the averaged values extracted from three samples for each type.

\begin{tabular}{lll}
\hline & Bare $\boldsymbol{p}$-Si & 3C-SiC/p-Si \\
\hline Carrier type & Holes & Holes \\
Sheet carrier concentration $\left(\mathbf{c m}^{-2}\right)$ & $1( \pm 0.2) \times 10^{14}$ & $1( \pm 0.2) \times 10^{14}$ \\
Mobility $\left(\mathbf{c m}^{\mathbf{2}} \mathbf{V}^{-1} \mathbf{s}^{-1}\right)$ & $341 \pm 10$ & $357 \pm 10$ \\
Sheet resistance $(\mathbf{\Omega} / \square)$ & $173 \pm 10$ & $166 \pm 10$ \\
\hline \hline
\end{tabular}

Table II shows the room temperature Hall measurement results of the low-doped p-Si substrate and 3C-SiC on p-Si. The low-doped p-Si substrate has p-type conduction with sheet carrier concentration, mobility and sheet resistance of $1( \pm 0.2) \times 10^{14} \mathrm{~cm}^{-2}, 341 \pm 10 \mathrm{~cm}^{2} \mathrm{~V}^{-1} \mathrm{~s}^{-1}$, and $173 \pm 10 \Omega / \square$, respectively. $3 \mathrm{C}$-SiC grown on the low-doped $\mathrm{p}$-Si also indicates p-type conduction with sheet carrier concentration of $1( \pm 0.2) \times 10^{14} \mathrm{~cm}^{-2}$, mobility of $357 \pm 10 \mathrm{~cm}^{2} \mathrm{~V}^{-}$ ${ }^{1} \mathrm{~S}^{-1}$, and sheet resistance of $166 \pm 10 \Omega / \square$, comparable to the bare low doped p-Si substrate. This implies that the SiC films grown on low-doped Si substrates are typically shorted and the charge carriers in the thick silicon substrate with relatively high mobility dominate the electrical conduction, as shown in Fig. 1(b). The electrical shorting persists even if we etch deep into the substrate, as long as the silicon charge carriers exists. ${ }^{8}$ Note that, we have systematically confirmed that the contacts are not shorting the substrate through the edges. ${ }^{7,8}$

(a)

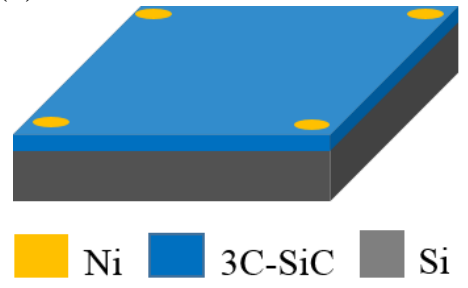

(b)

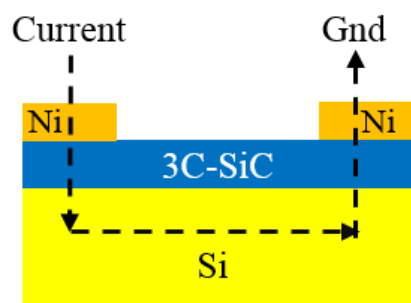

Region involved in conduction

FIG. 1. (a) Layout of the van der Pauw structure on 3C-SiC/Si, (b) schematic of electrical conduction path in the $\mathrm{SiC}$ grown at $1300-1400{ }^{\circ} \mathrm{C}$ on low-doped p-Si substrate. The whole silicon substrate is involved in the conduction through the injection of holes into the $\mathrm{SiC}$ layer. 
The electrical activity of the extended defects such as stacking faults (SF) and antiphase boundaries (APB) in SiC layers has been proposed in literature to explain the leakage in 3C$\mathrm{SiC}$ devices. ${ }^{2,3,14}$ In order to explore and potentially validate this hypothesis, we tested thicker films where the density of these defects are several orders of magnitude less than the thin films as reported by Song et al. ${ }^{2}$.

Table III shows the room temperature Hall characteristics of IMEM-CNR $500 \mathrm{~nm}$-thin $\mathrm{SiC}$ films on p-type $\mathrm{Si}\left(0^{\circ}\right), 5 \mu \mathrm{m}$-thick $\mathrm{SiC}$ films on both on-axis $\left(0^{\circ}\right)$ and $6^{\circ}$ off-axis $\mathrm{p}$-Si as well as the bare on-axis and off-axis p-Si substrates. We find that, the IMEM-CNR $500 \mathrm{~nm} 3 \mathrm{C}$ $\mathrm{SiC}$ films grown on on-axis $\mathrm{p}$-Si are also shorted to the substrate similar to the NOVASiC $3 \mathrm{C}$ SiC films. Moreover, Table III also clearly shows that the shorting is apparent even for the 5 $\mu \mathrm{m}$ thick $\mathrm{SiC}$ films grown on-axis $\mathrm{p}-\mathrm{Si}$ as the transport characteristics match the underlying substrate. In addition, the transport characteristics of the $5 \mu \mathrm{m}$ thick $3 \mathrm{C}$-SiC on $6^{\circ}$ off-axis p$\mathrm{Si}$, also exhibits electrical shorting with the substrate. If the extended defects in SiC layers were the main reason for the film-substrate shorting, the leakage would be reduced or absent in the thicker films. ${ }^{2}$

TABLE III. Hall measured transport characteristics at room temperature for IMEM-CNR thin $500 \mathrm{~nm}$ and thick $5 \mu \mathrm{m} \mathrm{SiC} \mathrm{films} \mathrm{grown} \mathrm{on} \mathrm{the} \mathrm{on-axis} \mathrm{p-Si} \mathrm{and} 6^{\circ}$ off-axis p-Si substrates. Results are the averaged values extracted from three samples for each type.

\begin{tabular}{llll|ll}
\hline \hline & \multicolumn{3}{c|}{$\mathrm{SiC}$ on on-axis p-Si } & \multicolumn{2}{c}{$\mathrm{SiC}$ on $6^{\circ}$ off-axis p-Si } \\
\hline & $\mathrm{p}-\mathrm{Si}$ & $500 \mathrm{~nm} \mathrm{SiC}$ & $5 \mu \mathrm{m} \mathrm{SiC}$ & $\mathrm{p}-\mathrm{Si}$ & $5 \mu \mathrm{m} \mathrm{SiC}$ \\
\hline Carrier type & Holes & Holes & Holes & Holes & Holes \\
Sheet carrier & $6( \pm 2) \times 10^{17}$ & $8( \pm 2) \times 10^{17}$ & $5( \pm 2) \times 10^{17}$ & $6( \pm 2) \times 10^{17}$ & $5( \pm 2) \times 10^{17}$ \\
concentration $\left(\mathbf{c m}^{-2}\right)$ & & & & & \\
Mobility $\left(\mathbf{c m}^{2} \mathbf{V}^{-1} \mathbf{s}^{-1}\right)$ & $70 \pm 10$ & $50 \pm 10$ & $65 \pm 10$ & $50 \pm 10$ & $50 \pm 10$ \\
Sheet resistance $(\boldsymbol{\Omega} / \square)$ & $0.17 \pm 0.01$ & $0.17 \pm 0.01$ & $0.17 \pm 0.01$ & $0.18 \pm 0.01$ & $0.18 \pm 0.01$ \\
\hline \hline
\end{tabular}

We performed SEM to determine the extent of extended defects in our samples. Fig. 2 shows an example SEM image of $500 \mathrm{~nm}$ thin SiC layers grown on on-axis p-Si and $5 \mu \mathrm{m}$ thick $\mathrm{SiC}$ grow on $6^{\circ}$ off-axis p-Si substrates. Fig. 2(a) shows that for thin epilayers, the stacking faults and antiphase boundaries are visible whereas, for the thick epilayers these defects are not visible, shown in Fig. 2(b). Thus, although the SEM evidence demonstrates fewer defects at the surface of the thick SiC layers, electrically there is no improvement in the shorting/leakage issue. This indicates that the extended defects in the SiC layers such as APB or SF probably do not substantially contribute to the leakage phenomenon. 

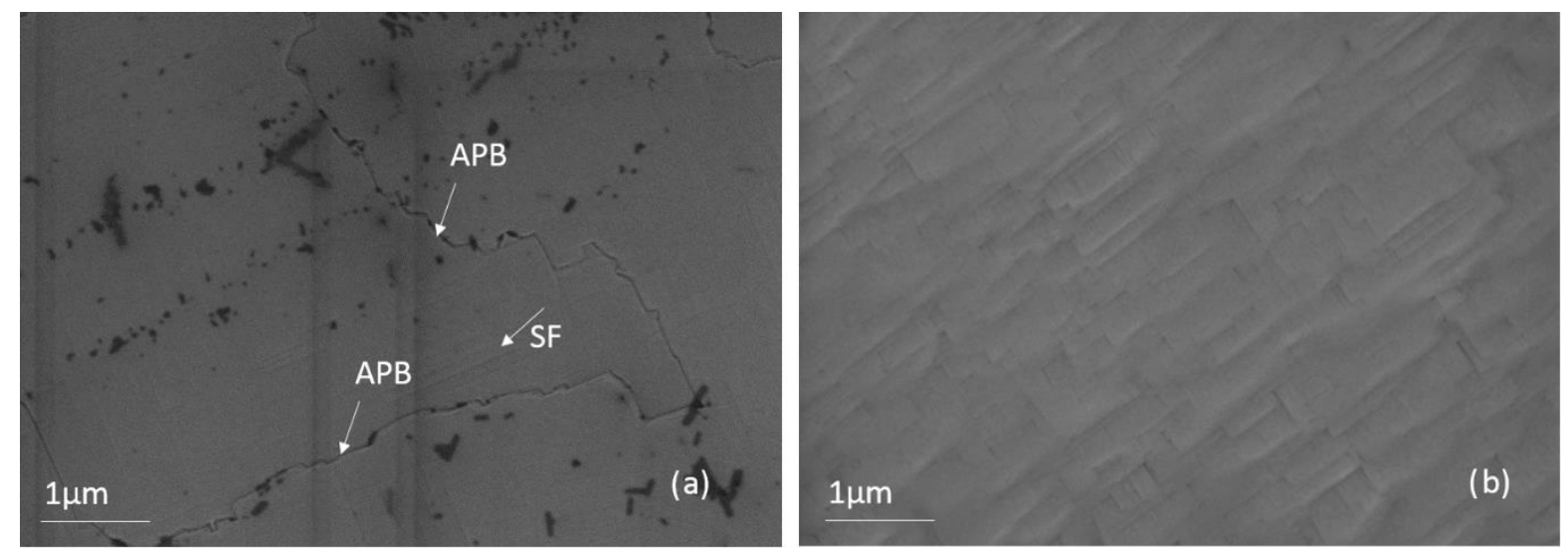

FIG. 2. Plane view SEM images for IMEM-CNR 3C-SiC (a) $500 \mathrm{~nm}$-thin SiC(100) film on on-axis p$\mathrm{Si}$; where antiphase boundaries (denoted APB) and stacking faults (denoted SF) are visible; (b) $5 \mu \mathrm{m}$ thick $\mathrm{SiC}(100)$ films on $6^{\circ}$ off-axis p-Si substrates; APBs and SFs are not visible

\section{Discussion and model}

In addition to the data presented here, indicating the electrical shorting of $\mathrm{SiC} / \mathrm{Si}$ films grown at a temperature of $1350^{\circ} \mathrm{C}$, we had also previously reported the occurrence of a similar phenomenon in $\mathrm{SiC}$ films grown at a lower temperature $\left(\sim 1000^{\circ} \mathrm{C}\right)$, after the samples were vacuum annealed at $1100^{\circ} \mathrm{C} .{ }^{7}, 8$ We noted that the electrical shorting was invariably accompanied by the relaxation of a considerable amount of compressive stress present at the $\mathrm{SiC} / \mathrm{Si}$ heterointerface $;^{7}$ which was a consequence of the combination of high temperature and high stress at the $\mathrm{SiC} / \mathrm{Si}$ interface enabling interatomic diffusions between $\mathrm{SiC}$ and $\mathrm{Si}^{15}$ Due to the stress relaxation at the $\mathrm{SiC} / \mathrm{Si}$ interface, we observed plastic deformation of the silicon substrate leading to a permanent change in the wafer curvature, becoming more convex (after annealing), as illustrated in Fig. 3.

Zielinski et al. also observed the occurrence of plastic deformation of the silicon substrate upon film growth when growth temperatures of $1300-1400^{\circ} \mathrm{C}$ were used. ${ }^{16,17}$ In this case, a permanent change of substrate curvature towards a less concave curvature was found, which was used to minimize the total bowing of the substrate upon growth. ${ }^{16,17}$ This was an important technological advance, since the significant tensile stress due to the lattice and thermal mismatch of the $\mathrm{SiC}$ on silicon system, especially for micron thick $\mathrm{SiC}$ films, would lead to an excessively concave wafer curvature. ${ }^{15}$ Such curvature would be particularly challenging for further wafer processing as well as device applications.

In addition, Anzalone et al., Camarda et al. and Watts et al., have reported for $\mathrm{SiC}$ grown at $1300^{\circ}-1400^{\circ} \mathrm{C}$ an intense compressive stress generated within the substrate capable 
of bowing the whole SiC/Si heterosystem downwards. ${ }^{18-20}$ These authors also proposed the stress originated from the early stage of growth (i.e. at the carbonization step), where unspecified "defects" are generated in the silicon substrate. ${ }^{18,19}$

Noting that the $\mathrm{SiC} / \mathrm{Si}$ samples studied in this work were all grown at high temperatures, similar to that of Zielinski et al., and that all of the samples have shown electrical shorting with the silicon substrate, it seems logical to expect that this phenomenon must be related to a permanent change (plastic deformation) of the substrate (convex) curvature. This permanent curvature change must occur whenever the top portion of the silicon substrate is driven into compression (see schematic in Fig.3). We propose that the compression in the top portion of the substrate is due to carbon diffusion into the silicon substrate matrix, as the carbon would expand the Si substrate lattice.

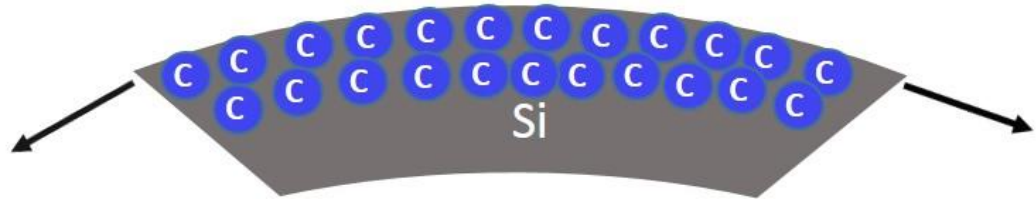

FIG. 3. Schematic of Si substrate bending into more convex due to the compressive stress exerted by the carbon interstitials within the top portion of silicon.

The guiding reasons for our hypothesis are that, due to the high stresses and high temperatures involved in $\mathrm{SiC}$ on $\mathrm{Si}$ heteroepitaxy, combined with a very high carbon-silicon miscibility (both elements are column IV), a considerable driving force for C and Si interdiffusion is anticipated in the interfacial region. Indeed, an out-diffusion of silicon forming typical interfacial voids, has been reported extensively in the literature. ${ }^{10,16}$ However, the possibility for microscopic atomic carbon diffusion into the silicon matrix has been largely overlooked, as opposed to the macroscopically evident silicon voids. In fact, we note that in all samples used for this work the silicon voids were intentionally suppressed by the vendors through engineering of the heteroepitaxial process.

Moreover, we expect carbon interstitials to affect $\mathrm{SiC} / \mathrm{Si}$ electrical junction properties. Note that when the carbon concentration in silicon exceeds the solubility of substitutional carbon $\left(\sim 10^{17} \mathrm{~cm}^{-3}\right.$ at $\left.1300^{\circ} \mathrm{C}\right),{ }^{21}$ interstitial carbon point defects are formed. ${ }^{22} \mathrm{~A}$ vast extent of atomic diffusion of carbon into the silicon substrate, would therefore lead to a significant amount of interstitial carbon, which would in turn drive the top portion of the substrate into compression while also strongly affecting the $\mathrm{SiC} / \mathrm{Si}$ electrical junction. 
Interstitial carbon, complexes between the interstitial and substitutional carbons or carbon precipitates may be electrically active and negatively affect the electrical characteristics of $p-n$ junctions ${ }^{22,23}$ resulting in substantial leakage, or even plain electrical shorting, since such defects act as an additional conduction path for charge carriers. The carbon interstitials can behave as deep acceptors in silicon with an activation energy of $0.35 \mathrm{eV}$ from the valence band (hole traps) $^{23}$, and assist compensation of unintentional donors in the SiC film as well as hole injection from the $\mathrm{Si}$ substrate across the $\mathrm{Si} / \mathrm{SiC}$ interface further reducing the effectiveness of p-n junction. 4

Hence, the generation of a considerable amount of interstitial carbon defects in the top portion of silicon upon high temperature epitaxy, would explain both the mechanical and the electrical behaviour observed in the $\mathrm{SiC} / \mathrm{Si}$ system.

We simulated the effect of interstitial carbon on the junction between $\mathrm{SiC}$ and the lowdoped p-Si substrate using Technology Computer-Aided Design (TCAD) simulations, performed at $1 \mathrm{~V}$ bias, using the parameters summarized in Table IV.

The initial n-type doping concentration for the $\mathrm{SiC}$ films was set to $1 \times 10^{19} \mathrm{~cm}^{-3}$ according to the value in Pradeepkumar et al., measured prior to the degradation of the p-n junction (see Table IV and Fig. 4(a)). ${ }^{7}$ Hole -type doping for the silicon was set at $1.3 \times 10^{15}$ $\mathrm{cm}^{-3}$ as per Hall measurements of the bare p-Si in Table II (see Fig. 4(b)). The electronic defects in the silicon were subsequently introduced in the calculation, assuming an ionization energy of $0.35 \mathrm{eV}$ from the valence band (hole traps, deep acceptors) as reported for interstitial carbon in silicon by Simoen et al. ${ }^{23}$ The simulations accounting for the interstitial defects show that an acceptor density of about $10^{20} \mathrm{~cm}^{-3}$ in the silicon is sufficient in order to invert the conduction of the SiC film from n-type to p-type (Fig. 4(c) and 4(d)).

Table IV. Simulation parameters.

\begin{tabular}{lllll}
\hline \hline & $\begin{array}{l}\text { Thickness } \\
(\boldsymbol{\mu m})\end{array}$ & $\begin{array}{l}\text { Doping } \\
\left(\mathbf{c m}^{-\mathbf{3}}\right)\end{array}$ & $\begin{array}{l}\text { Hole trap density } \\
\left(\mathbf{c m}^{-\mathbf{3}}\right)\end{array}$ & $\begin{array}{l}\text { Ionization energy } \\
(\mathbf{e V})\end{array}$ \\
\hline \hline 3C-SiC & 0.5 & $1 \times 10^{19}(\mathrm{n})$ & - & - \\
$\mathrm{Si}$ & 527 & $1.3 \times 10^{15}(\mathrm{p})$ & $1 \times 10^{20}$ & 0.35 \\
\hline
\end{tabular}



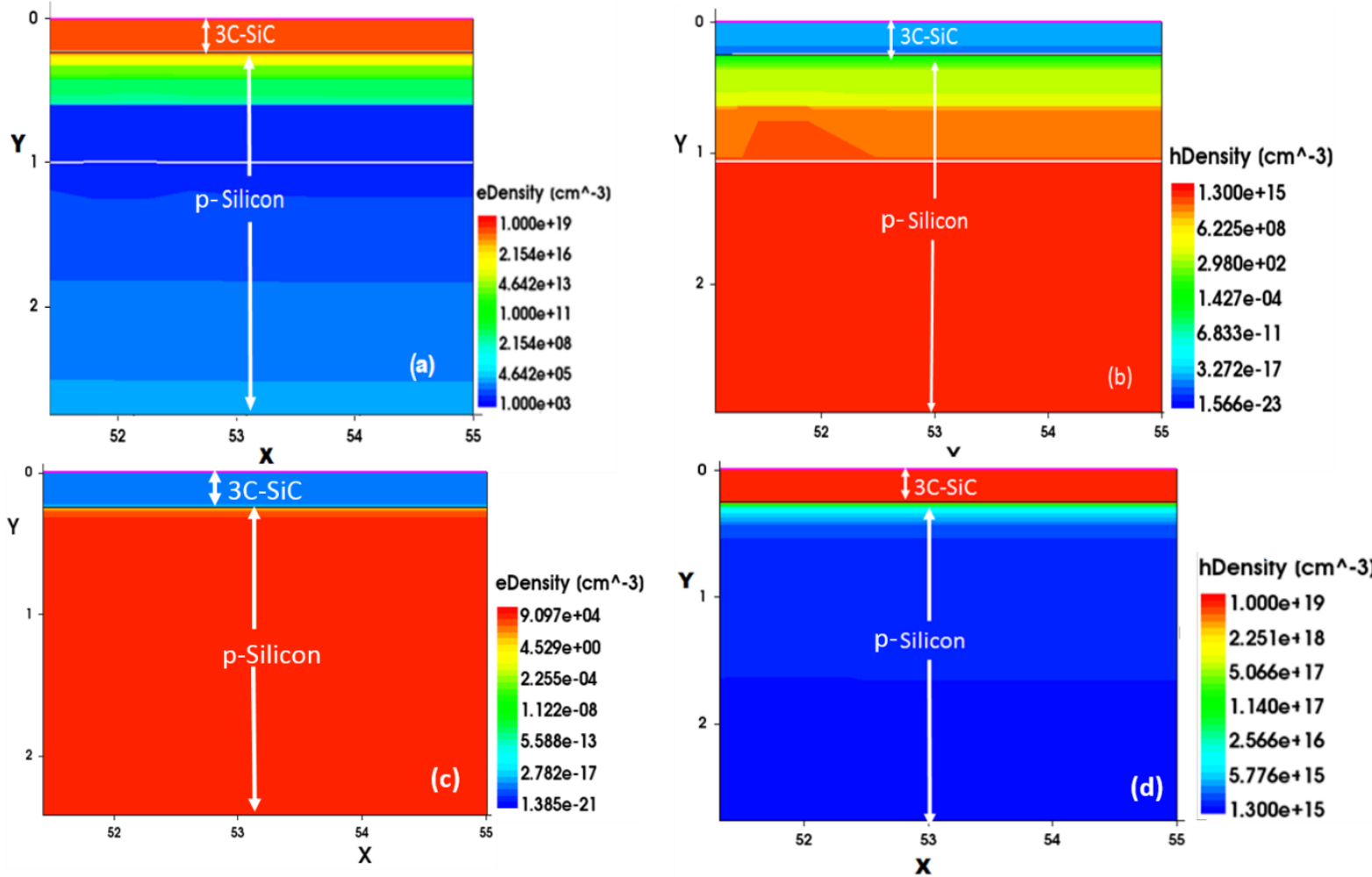

FIG. 4. TCAD simulation results of the 3C-SiC on low doped p-Si substrate (a) electron density and (b) hole density, in the SiC/Si system before junction degradation (no defects); (c) electron density and (d) hole density, in the $\mathrm{SiC} / \mathrm{Si}$ system after incorporating interstitial carbon degradation within silicon.

Therefore, the degradation of the p-n junction at the interface of the $\mathrm{n}$-SiC film on $\mathrm{p}$ silicon (upon growth or high temperature annealing) can be explained by the presence of electrically active interstitial carbon acceptor traps in excess of $10^{20} \mathrm{~cm}^{-3}$ within the top portion of the substrate.

For completeness, we note that an additional potential reason for the degradation of the $\mathrm{SiC} / \mathrm{Si}$ junction could be the reduced band gap arising from the residual tensile strain in the $\mathrm{SiC}$ epilayers. ${ }^{9}$ That is, the band gap reduction results in a smaller valence band barrier and leads to increased hole current injection from the Si to the SiC. ${ }^{9}$ To test the hypothesis of tensile strain-induced $\mathrm{SiC}$ band gap changes on the junction we simulated the $\mathrm{SiC} / \mathrm{Si}$ system with the strained band gap and electron affinity values mentioned by Rahimi et al. ${ }^{9}$ and found that even a large concentration of those acceptor traps (up to $\sim 10^{20} \mathrm{~cm}^{-3}$ ) in the film does not appreciably contribute to the degradation of the heterojunction between the SiC film and the substrate. 


\section{B. 3C-SiC on high-resistivity silicon}

\section{Results}

In an attempt to electrically insulate the silicon carbide film from the silicon substrate, we have used a high-resistivity silicon as the substrate, as opposed to p-type doped silicon.

Table V shows the room temperature van der Pauw Hall measurement results of 3C$\mathrm{SiC}$ grown on high-resistivity $\mathrm{Si}$ as well as the representative bare $\mathrm{Si}$ substrate. High-resistivity silicon shows n-type conduction, with a sheet carrier concentration of $1( \pm 2) \times 10^{10} \mathrm{~cm}^{-2}$, mobility of $1220 \pm 10 \mathrm{~cm}^{2} \mathrm{~V}^{-1} \mathrm{~s}^{-1}$, and sheet resistance of $500 \pm 3 \mathrm{k} \Omega / \square$.

After the $\mathrm{SiC}$ film growth on the high-resistivity $\mathrm{Si}$, the transport characterisation showed a carrier concentration one order of magnitude higher, and the sheet resistance one order of magnitude smaller compared to the bare substrate. However, even after completely removing the $\mathrm{SiC}$ layer using ICP etching, the Hall measured characteristics remained largely unaffected and consistent with the values before the removal of the $\mathrm{SiC}$ layer. Note that the complete removal of SiC layer has been confirmed using an Energy Dispersive X-Ray Analysis after etching.

The similar transport characteristics before and after the removal of SiC layer clearly indicate that the $\mathrm{SiC}$ is not responsible for the measured electrical conduction. To clarify this and discern the origin of the conduction in $\mathrm{SiC} /$ high-resistivity $\mathrm{Si}$, we measured the leakage resistances between $\mathrm{SiC}$ mesas on the high-resistivity $\mathrm{Si}$ using the TLM method as shown in Fig. 5.

Table V. Hall measured transport characteristics at room temperature. Results are the averaged values extracted from three samples for each type.

\begin{tabular}{llll}
\hline \hline & High-resistivity & $\begin{array}{l}\text { SiC/high- } \\
\text { resistivity Si }\end{array}$ & $\begin{array}{l}\text { Removed SiC/high- } \\
\text { resistivity Si }\end{array}$ \\
\hline \hline Carrier type & Electrons & Electrons & Electrons \\
Carrier concentration $\left(\mathbf{c m}^{-\mathbf{2}}\right)$ & $1( \pm 2) \times 10^{10}$ & $3( \pm 2) \times 10^{11}$ & $4( \pm 2) \times 10^{11}$ \\
Mobility $\left(\mathbf{c m}^{\mathbf{2}} \mathbf{V}^{-1} \mathbf{s}^{-1}\right)$ & $1220 \pm 10$ & $1677 \pm 10$ & $1650 \pm 10$ \\
Sheet resistance $(\mathbf{k} \mathbf{\Omega} / \square)$ & $500 \pm 3$ & $12 \pm 3$ & $12 \pm 3$ \\
\hline \hline
\end{tabular}



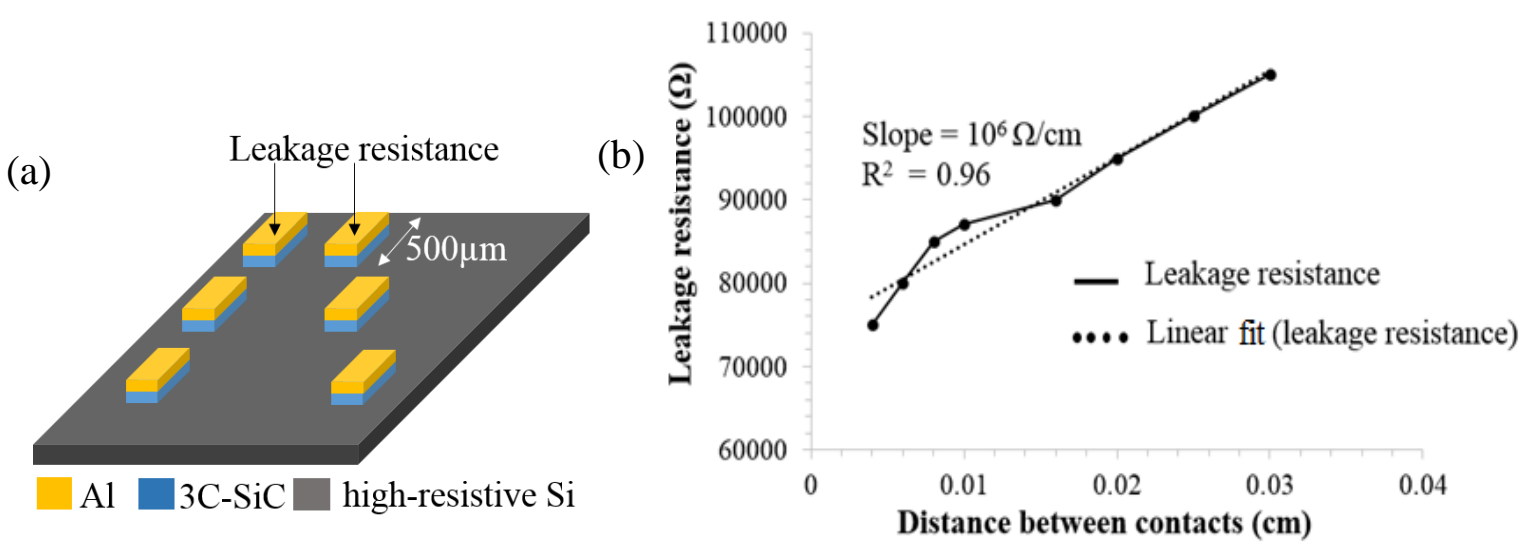

FIG. 5. a) TLM structures on the 3C-SiC/high-resistivity Si, b) Fitted TLM leakage resistances versus contact spacing for $\mathrm{SiC}$ on high-resistivity $\mathrm{Si}$

Fig. 5b shows the fitted leakage resistances obtained using TLM structures on the $\mathrm{SiC} /$ high-resistivity $\mathrm{Si}$ as a function of different contact spacing with a slope of $10^{6} \Omega \mathrm{cm}^{-1}$. The sheet resistance obtained experimentally from slope and width of the contact is $\sim 50 \mathrm{k} \Omega / \square$, about the same order of magnitude of the sheet resistance obtained from the Hall measurements in TABLE II after growth and/or removal of the SiC. Based on the specification of the highresistivity substrate, we would expect a $500 \mathrm{k} \Omega / \square$ of sheet resistance for the TLM measurement. In conclusion, both van der Pauw and TLM measurements indicate that after the growth of $\mathrm{SiC}$ on the high-resistivity silicon, a leakage path is created in a region below the interface, which is not removed by the etching of the SiC.

We suggest that the presence of additional carriers in the order of $\sim 10^{11} \mathrm{~cm}^{-2}$ within the high-resistivity silicon forming a leakage path below the interface can be attributed once again to the carbon out-diffusion into silicon forming interstitial carbon. Sze indicates that the interstitial carbon in an n-type silicon acts as a donor with a defect level of $0.25 \mathrm{eV}$ from the conduction band, creating effectively an n-type doping. ${ }^{24}$ The presence of interstitial carbon point defects within the silicon can thus form a leakage path within the top portion of the highresistivity substrate. The schematic representation of the electrical conduction in $3 \mathrm{C}-\mathrm{SiC}$ on high-resistivity silicon is given in Fig. 6. 


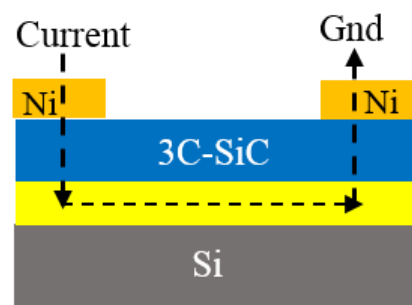

Region involved in conduction

FIG. 6. Schematic of conduction path in $3 \mathrm{C}-\mathrm{SiC} /$ high-resistivity $\mathrm{Si}$ grown at $1300-1400{ }^{\circ} \mathrm{C}$-the conduction occurs within a region of a few micrometres thick below the interface.

\section{Practical solution for the 3C-SiC/Si in-plane leakage}

Based upon the conduction path sketched in Figure 6, we would expect that removing the conductive portion of the silicon could resolve the leakage problem in the SiC/highresistivity $\mathrm{Si}$ system.

Table VI (a) shows that after etching away the conductive region in the silicon below the $\mathrm{SiC} / \mathrm{Si}$ interface we obtain a van der Pauw sheet resistance of $492 \pm 2 \mathrm{k} \Omega / \square$ indicating an acceptable electrical isolation between the $\mathrm{SiC}$ mesas. The leakage resistances for the $\mathrm{SiC} / \mathrm{high}$ resistivity Si using TLM structures after the removal of the conductive region is $\sim 10 \mathrm{M} \Omega$, indicating that leakage is eliminated within the SiC/Si system, see Table VI (b).

Table VI. Electrical characteristics at room temperature for SiC/high-resistivity Si before and after 20 $\mu \mathrm{m}$ deep etching of silicon between SiC pillars a) van der Pauw Hall measurement results b) TLM leakage resistance results. Results after etching are the averaged values of two samples each.

(a)

Carrier type

Sheet carrier concentration $\left(\mathrm{cm}^{-2}\right)$

Mobility $\left(\mathrm{cm}^{2} \mathrm{~V}^{-1} \mathrm{~s}^{-1}\right)$

Sheet resistance $(k \Omega / \square)$

\section{SiC/high-resistivity \\ SiC/high-resistivity} Si

(before etching)

Electrons

$3( \pm 2) \times 10^{11}$

$1677 \pm 10$

$12 \pm 3$ Si

(after $20 \mu \mathrm{m}$ etch)

Electrons

$5( \pm 2) \times 10^{11}$

$34 \pm 10$

$492 \pm 2$ 
(b)

\begin{tabular}{lll}
\hline \hline Contact spacing & \multicolumn{2}{c}{ TLM leakage resistance } \\
\hline \hline$(\boldsymbol{\mu m})$ & before etch $(\mathbf{k} \boldsymbol{\Omega})$ & after $\mathbf{2 0} \boldsymbol{\mu m}$ etch $(\mathbf{M} \boldsymbol{\Omega})$ \\
\hline 40 & 75 & 8.5 \\
60 & 80 & 8.5 \\
80 & 85 & 9.5 \\
100 & 87 & 10 \\
160 & 90 & - \\
200 & 95 & 10 \\
\hline \hline
\end{tabular}

From both the van der Pauw and TLM results we find that in order to completely isolate the $\mathrm{SiC}$ mesas, we need to etch at least $20 \mu \mathrm{m}$ deep into the high-resistivity silicon between the SiC pillars, see Figures 7(a) and 7(b).

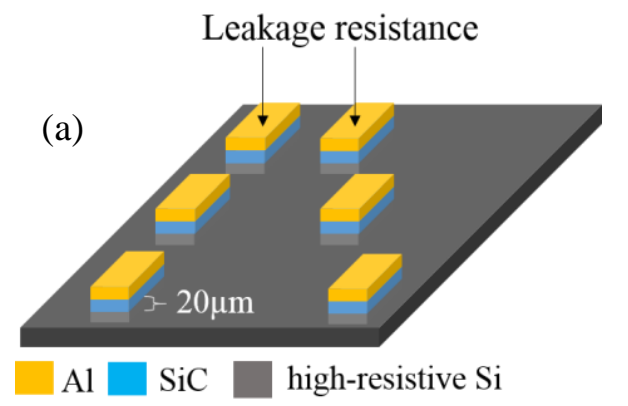

(b)

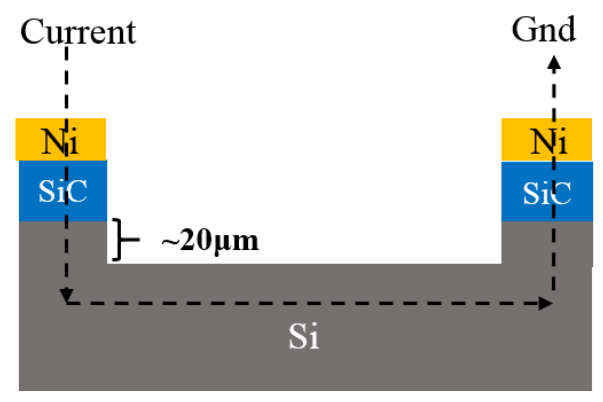

Fig. 7. SiC/high-resistivity Si after $\sim 20 \mu \mathrm{m}$ deep etching of Si (a) TLM structure, (b) electrical conduction

\section{CONCLUSION}

The scope for application of heteroepitaxial 3C-SiC films grown on $\mathrm{Si}$ is typically limited by the electrical instability of the heterointerface. Although this limitation was already known in the scientific community, the reason for this instability had not been addressed. Here we show that, upon epitaxial growth at high temperature, this electrical instability is due to the diffusion $^{25}$ of carbon atoms into the underlying silicon matrix forming electrically active interstitial carbon defects, which also results in strong compression for the top portion of the substrate.

When considering epitaxial SiC on a p-type silicon substrate, we have shown that an interstitial carbon concentration in silicon in excess of $10^{20} \mathrm{~cm}^{-3}$ can invert the conduction in the $\mathrm{SiC}$ from n-type to p-type due to the generated acceptor traps (interstitial carbon in silicon forming a mid- bandgap level at $0.35 \mathrm{eV}$ ), destroying the electrical junction. When a highly resistive silicon substrate is used instead, we have shown that atomic carbon diffusion within 
the top portion of silicon generates a leakage path below the SiC/Si heterointerface. We can attribute this phenomenon again to the interstitial diffusion of carbon, generating additional ntype carriers in silicon due to the second type of electronic defect associated with interstitial carbon, which is a donor level $0.2 \mathrm{eV}$ from the conduction band. Nevertheless, we have also demonstrated that we can achieve electrical isolation of SiC mesas on high-resistivity silicon substrates by etching away at least $20 \mu \mathrm{m}$ into the silicon between the SiC structures.

We also conclude that the electrical instability of the $\mathrm{SiC}$ on silicon system is a universal underlying problem associated with direct epitaxial synthesis, no matter the epitaxial approach used, although certainly conditions such as temperature are expected to influence the extent of this phenomenon. Therefore, this work clarifies a long-standing issue in the SiC community.

\section{ACKNOWLEDGEMENTS}

The authors acknowledge the funding support from the AFOSR through the Grant No. AOARD 15IOA053, as well as the software access support from Australian National Fabrication Facility Design House Virtual Lab by Shan Don (ANFF). Office of Naval Research also supports D. K Gaskill.

${ }^{1}$ H. Y. Nishino S, Matsunami H and Tanaka T, J. Electrochem. Soc. 127, 2674-2680 (1980)

${ }^{2}$ X. Song, J. Michaud, F. Cayrel, M. Zielinski, M. Portail, T. Chassagne, E. Collard and D. Alquier, Appl. Phys. Lett. 96, 142104 (2010)

${ }^{3}$ J. Michaud, M. Portail and D. Alquier, Advanced Silicon Carbide Devices and Processing (InTech, 2015) p.256

${ }^{4}$ P. Tanner, A. Iacopi, H.-P. Phan, S. Dimitrijev, L. Hold, K. Chaik, G. Walker, D. V. Dao and N.-T. Nguyen, Sci. Rep. 7, 17734 (2017)

${ }^{5}$ A. Steckl, C. Yuan, Q. Y. Tong, U. Gösele and M. Loboda, J. Electrochem. Soc. 141, L66L68 (1994)

${ }^{6}$ W. Reichert, E. Obermeier and J. Stoemenos, Diam. Relat. Mater. 6, 1448-1450 (1997)

${ }^{7}$ A. Pradeepkumar, N. Mishra, A. R. Kermany, J. J. Boeckl, J. Hellerstedt, M. S. Fuhrer and F. Iacopi, Appl. Phys. Lett. 109, 011604 (2016)

${ }^{8}$ A. Pradeepkumar, N. Mishra, A. R. Kermany, J. J. Boeckl, J. Hellerstedt, M. S. Fuhrer and F. Iacopi, Appl. Phys. Lett. 109, 196102 (2016)

${ }^{9}$ R. Rahimi, C. Miller, S. Raghavan, C. Stinespring and D. Korakakis, J. Phys. D: Appl. Phys. 42, 055108 (2009)

${ }^{10}$ M. Suemitsu, S. Jiao, H. Fukidome, Y. Tateno, I. Makabe and T. Nakabayashi, J. Phys. D: Appl. Phys. 47, 094016 (2014)

${ }^{11}$ M. Zielinski, M. Portail, S. Roy, T. Chassagne, C. Moisson, S. Kret and Y. Cordier, Mater. Sci. Eng., B 165, 9-14 (2009)

${ }^{12}$ M. Bosi, G. Attolini, M. Negri, C. Frigeri, E. Buffagni, C. Ferrari, T. Rimoldi, L. Cristofolini, L. Aversa and R. Tatti, J. Cryst. Growth. 383, 84-94 (2013)

${ }^{13}$ M. Bosi, C. Ferrari, D. Nilsson and P. Ward, CrystEngComm. 18, 7478-7486 (2016) 
${ }^{14}$ C. A. J. Ammerlaan, A. Chantre and P. Wagner, Science and Technology of Defects in Silicon North Holland, 1990) p.518

${ }^{15}$ F. Iacopi, R. E. Brock, A. Iacopi, L. Hold and R. H. Dauskardt, Acta Mater. 61, 6533-6540 (2013)

${ }^{16}$ M. Zielinski, A. Leycuras, S. Ndiaye and T. Chassagne, Appl. Phys. Lett. 89, 131906 (2006)

${ }^{17}$ M. Zielinski, S. Ndiaye, T. Chassagne, S. Juillaguet, R. Lewandowska, M. Portail, A. Leycuras and J. Camassel, Phys. Status Solidi A 204, 981-986 (2007)

${ }^{18}$ R. Anzalone, M. Camarda, C. Locke, J. Carballo, N. Piluso, A. La Magna, A. A. Volinsky, S. E. Saddow and F. La Via, J. Mater. Research. 28, 129-135 (2013)

${ }^{19}$ B. E. Watts, G. Attolini, T. Besagni, M. Bosi, C. Ferrari, F. Rossi, F. Riesz and L. D. Jiang, Mater. Sci. Forum. 679, 137-140 (2011)

${ }^{20}$ M. Camarda, R. Anzalone, A. La Magna and F. La Via, Thin Solid Films. 522, 26-29 (2012)

${ }^{21}$ U. Gosele, Oxygen, Carbon, Hydrogen and Nitrogen in crystalline silicon (Materials Research Society, Pittsburg, USA, 1986) p.419

${ }^{22} \mathrm{P}$. Pichler, Intrinsic Point Defects, Impurities, and Their Diffusion in Silicon (Springer, Vienna, 2004) p.281-329

${ }^{23}$ E. Simoen, S. Dhayalan, A. Hikavyy, R. Loo, E. Rosseel, H. Vrielinck and J. Lauwaert, ECS J. Solid State Sci. Technol. 6, 284-289 (2017)

${ }^{24}$ S. Sze, Semiconductor Devices: Physics and Technology, John Willey \& Sons (John Willey \& Sons, New York, 1985)

${ }^{25}$ A. Tipping and R. Newman, Semicond. Sci. Technol. 2, 315 (1987) 